\title{
Detection of E6/E7 human papilloma virus (HPV) transcripts in lymph nodes of patients with cervical cancer
}

\author{
Jorge Alejandro Basiletti ${ }^{1}$, Alejandro Soderini ${ }^{2,3}$, María Alejandra Picconi ${ }^{1}$, Nicasio Cuneo ${ }^{3}$, Silvia Vornetti ${ }^{3}$, Mercedes Rodríguez de la Peña ${ }^{4}$, \\ Juan Mural ${ }^{4}$, Claudia Kottar ${ }^{4}$, Cecilia Lagues ${ }^{4}$, María Graciela Etcheverry ${ }^{5}$, Diego Zurita ${ }^{5}$, Adriana Greco ${ }^{2}$, Elsa Haas ${ }^{1}$, Carlos Reyes ${ }^{2}$ and \\ Lidia Virginia Alonio ${ }^{1 *}$
}

${ }^{1}$ Instituto Nacional de Enfermedades Infecciosas, ANLIS “Carlos G. Malbrán”, Argentina

${ }^{2}$ Hospital General de Agudos "Parmenio Piñero”, Argentina

${ }^{3}$ Hospital Municipal de Oncología "Marie Curie”, Argentina

${ }^{4}$ Hospital Nacional "Profesor Alejandro Posadas", Argentina

${ }^{5}$ Hospital Municipal “Juan A. Fernández”, Argentina

\begin{abstract}
Persistent high risk Human Papillomavirus (HPV) infection is necessary for the development of cervical cancer (CC). HPV carcinogenesis is based on viral E6 and E7 proteins' capacity to interfere in cell proliferation control. The metastasis status of pelvic lymph nodes (PLN) is a critical parameter in post-operative decisions on adjuvant therapy, given its strong correlation with recurrence in CC. In order to complement the histopathological evaluation of subclinical node metastases, we evaluated the application of a commercial HPV E6 / E7 mRNA kit, to detect viral messenger RNAs in lymph nodes and tumors of patients with CC.

Forty five cervical primary tumors and 152 PLN ( 3-4 from each patient) were included. HPVs were typed in tumors by PCR (polymerase chain reaction) using generic primers PGMY and reverse line blot hybridization (RLB) with type-specific oligo probes corresponding to $37 \mathrm{HPV}$ types that infect the anogenital tract. PNL were collected in RNAlater (Invitrogen) and mRNA was extracted using the MiniMag (Biomerieux) system. Detection of E6 and E7 mRNAs corresponding to HPVs types 16, 18, 31, 33 and 45 was carried out using isothermal real time PCR (NucliSENS EasyQHPV, Biomerieux).

HPV was detected in the tumors of 42 patients; the viral types identified were HPV16 ( $n=32)$, HPV18 ( $=5$ ), HPV31 ( $=3$ ), HPV45 ( $=2$ ), HPV59 ( $=1$ ) and HPV73 $(n=1)$. These last 2 cases were not considered in the study because the mRNA detection system does not include these viral types. Also excluded were 2 cases whose tumors were HPV negative. There was a high correlation between the histological and virological results. Seventy-two percent of the histologically positive PLN were positive for E6-E7 mRNA; while 93\% (125/134) of the negative PLN were also negative for E6-E7 mRNA assay. There was, however 8\% (9/134) of negative PLN in which viral messengers were detected.
\end{abstract}

Patients' follow up was limited (4 years) and except for two patients who died (both positive for HPV 45) in the period under review, no recurrences were recorded in any of the patients included in the study.

The presence of HPV in PLN may indicate a metastasis, as since the virus is not able of producing viremia or invading tissues it can only be "transported" by the cancer cell. The presence of HPV mRNA indicates viral genome transcription, a process which occurs in a lymph node only in CC metastatic cells, as these viruses can only replicate in epithelial-origin cells. Therefore, the findings of these mRNAs in the negative pelvic lymph nodes point out a very early metastasis, detectable at molecular level, but unobservable on histological diagnosis.

The commercial kits for HPV E6/E7 mRNA detection, usually applied for the cervical disease management, may be used also to evaluate PLN biopsies, in hospitals without high complexity laboratories. The test might be a tool to complement morphological observation, particularly when PLN do not exhibit characteristics compatible with invasion, thus optimizing monitoring and decision making.

\section{Introduction}

Epidemiological and molecular studies have shown that human Papillomavirus (HPV) are associated with the development of preneoplastic and neoplastic lesions of the anogenital tract. PVs are absolutely species and tissue specific since they only replicate in epithelial tissue; replication and expression of late viral proteins (capsid) occur only in cells with some degree of differentiation. PVs do not kill the cell they infect; but rather coexist with it, without penetrating under the basement membrane or establishing viremia [1,2].

Over 100 viral types are known, classified on the basis of DNA homology. Almost half of them are detected in the anogenital tract, and their genetic variability relates to their carcinogenicity. The viral types that taxonomically correspond to A7 (HPV 18, 39, 45, 59 and 68) and A9 species (HPV 16, 31, 33, 35, 52 and 58) include most of the so called high risk types, being types 16 and 18 responsible for about $60-75 \%$ of all precursor lesions and squamous invasive cancers

Correspondence to: Lidia Virginia Alonio, PhD, Inst. Nacional de Enfermedades Infecciosas, ANLIS “Carlos G. Malbrán”, Address: Av. Vélez Sársfield 563, Buenos Aires, Argentina, Tel: 54114301 7428,E-mail: alonio@anlis.gov.ar

key words: HPV, E6-E7mRNA, cervical cancer, sub clinical metastasis, lymph node, pelvic lymphadenectomy

Received: September 20, 2017; Accepted: October 14, 2017; Published: October 17,2017 
worldwide, with few regional variations. Almost all adenocarcinomas are caused only by HPVs 16, 18 and 45 [3-5]. Types 16 and 18 are more aggressive, developing earlier lesions and having a much greater risk of progression than other oncogenic types.

HPV carcinogenesis is based on the ability of certain high risk viral proteins to interfere with cell proliferation control. In severe preneoplastic lesions and cancers, viral DNA is frequently integrated into the genome of the infected cell. This involves breaking the E2 viral gene, leading to over-expression of viral oncoproteins E6 and E7, and cellular genome destabilization. It was shown in vitro that the high-risk HPV E6 and E7 oncoproteins bind with high affinity to tumor suppressor cell proteins $\mathrm{p} 53$ and pRB (retinoblastoma protein), respectively, and subsequently degrade them. Other cell targets would also be affected by E6 and E7. As a result of the interactions of viral oncoproteins, there is excess mitosis and deactivation of apoptosis mechanisms causing sustained genetic instability which induces malignant transformation [6,7].

Several methodological strategies including commercial tests, exist to detect viral mRNAs [8]. Most of them target high-risk HPV E6 and E7 oncogenes [9]. Unlike DNA testing that only provides information about the presence of infection and the viral type, the detection of E6 and E7 mRNA identifies HPV genotypes most frequently found in cervical cancer $(16,18,31,33$ and 45$)$ and is also indicative of the expression of oncoproteins E6 and E7 of these viruses, which have been directly associated with malignant transformation. The test thus provides a higher positive predictive value than DNA as to the viral carcinogenic activity [8]. Several recent studies have shown that these tests may be clinically useful because of their greater specificity to detect cervical conditions $[9,10]$.

Detection of HPV DNA in histologically normal lymph nodes of patients with cervix, vulva and penis cancer, using highly sensitive technologies such as PCR, has led to speculation that it could indicate an early metastasis or micrometastasis overlooked in the histological test [11-16]. Nodal metastasis is an important parameter in postoperative adjuvant therapy decisions, given its strong correlation with recurrence. Radical hysterectomy with pelvic lymphadenectomy is a widely disseminated treatment for Ib-IIa cervical cancer stages, with excellent survival rates above $80 \%$ [17-19]. Despite these good results, $20 \%$ of patients develop recurrences and eventually die [20].

Patients with negative PLNs have a low risk of recurrence, but in absolute numbers they account for $50 \%$ of all cervical cancer recurrences $[18,19]$. In patients with negative PLNs, many risk factors have been proposed and evaluated, such as tumor size, stromal invasion, lymphovascular invasion, microscopic parametric infiltration, etc, whose presence would decide adjuvant radiotherapy (RT), but data are not consistent and uniform in different studies [21,22].

Strict indications of RT in patients with negative PLNs are not well defined, it is therefore important to identify risk groups that may benefit from adjuvant therapy.

The presence of HPV DNA in lymph nodes could be an indicator of metastasis, since viral DNA is integrated into the cancer cell genome. However, the results of different studies have been controversial. [1316]. In our previous study group, it was noted that the presence of HPV DNA in tumor free PLNs did not necessarily indicate metastasis, but could be associated with an active immune reaction [14]. In order to link viral presence in the histological negative PLN with early metastasis the virus should be proven really active and not a mere passenger. A signal of HPV activity is the detection of its messenger RNAs (mRNAs), which indicate viral genome transcription. Because these viruses can only be expressed in epithelial cells, such expression is expected to occur only in metastatic cervical carcinoma cells.

On the other hand, diagnostic tools are necessary to complement surgery and morphology information in determining the overall status of the disease.

\section{Objective}

In order to complement the histopathological evaluation to detect subclinical node metastases, we have evaluated the application of a commercial kit to detect viral E6/E7 RNA messengers in the primary tumors and lymph nodes of patients operated for cervical cancer

\section{Patients, materials and methods}

Forty five patients (ages 19-67, mean 40.5) with stage IB cervical cancer, treated at public hospitals from Argentina were included in the study. Only patients who had not been previously irradiated were enrolled. All patients were required to sign an informed consent after providing essential information about the project approved by each hospital's Ethics Committee.

\section{Collecting samples for pathological and virological studies}

Forty five primary cervical tumor biopsies and 152 pelvic lymph nodes (PNL) were studied, between 3 and 4 PLN average per patient. To avoid contamination or degradation of the samples, during surgery sequential resection was performed as follows: 1) 3-4 pelvic PLN identifying them for comparing with the pathology results; 2) cervical tumor; in each case changing the scalpel and forceps.

From each PLN and tumor, a portion of about $0.5 \mathrm{~cm}$ was collected for virological studies. In order to keep on file, in case of a possible histological review, an imprint of the excised portion was performed on a sterile glass slide (RNAse free) which was fixated and saved at the Pathology section.

The PLN fragments and primary tumor obtained were cut and fractionated in a sterile Petri dish and placed in an Eppendorf tube containing RNAlate, (Invitrogen) to avoid degradation of tissue mRNA. The remaining material was fixed as usual for pathological studies $(10 \%$ buffered formalin). In each step, extreme care was taken not to create contamination between the tumor and the PLNs, changing forceps and scalpel each time.

In cases where the tumor could not be seen in the surgical specimen or only the previously extracted cone material was available, 5 serial sections of $5 \mu \mathrm{m}$ were cut from the fixed and paraffin-embedded material.

\section{Viral DNA extraction from tumors}

The fragments of each fresh tumor were resuspended in approximately $100-500 \mathrm{ul}$ of digestion buffer $(10 \mathrm{mM}$ Tris $(\mathrm{pH} 8.3)$ $0.45 \%$ Tween-20, 0.45\% Igepal CA-630 supplemented with $500 \mu \mathrm{g} / \mathrm{ml}$ Proteinase K) depending on tissue size, then incubated for 3 hours at $56^{\circ} \mathrm{C}$ until complete digestion. This product was used as a template for subsequent analysis by PCR reaction.

When only fixed and paraffin-embedded material was available, tissue sections were deparaffinized, hydrated and digested with proteinase K supplemented buffer. Nucleic acids were extracted and purified using columns (Qiagen) following manufacturer's instructions.

Once the DNA was obtained, it was suspended in TE buffer and stored at $-20^{\circ} \mathrm{C}$ until analyzed. 


\section{Lymph node viral RNA extraction purification}

Each PLN was previously placed in $2 \mathrm{ml}$ microtubes containing $1 \mathrm{ml}$ of lysis buffer (NucliSens lysisbuffer, BioMerieux); then homogenized using the Homogenizer Pro200 (Pro Scientific) equipment for 15-30 seconds and incubated in dry block for 30 minutes at $37^{\circ} \mathrm{C}$.

Purification: 100 ul of the lysate were diluted in a $1.5 \mathrm{ml}$ microtube containing $900 \mathrm{ul}$ of lysis buffer (NucliSens lysisbuffer, BioMerieux). It was vortexed briefly, $100 \mathrm{ul}$ of this dilution were taken and further diluted in 900 ul of lysis buffer (NucliSens lysisbuffer, BioMerieux). This dilution was used to purify mRNA with the NucliSens MiniMag (Biomerieux) system. After numerous and successive steps involving bonding the material to magnetic particles and washing with different buffer solutions, the final elution was performed. Purified mRNAs were transferred to a new $1.5 \mathrm{ml}$ tube and stored at $-70^{\circ} \mathrm{C}$ until analysis.

\section{HPV detection and genotyping}

For HPV detection direct PCR was applied using generic consensus primers PGMY09, 11 that amplify a 450bp fragment of the L1 region of mucosotropic HPV genome [23].

PGMY09, 11 PCR was developed on a final volume of 50 microliters containing $1 \mathrm{X}$ buffer solution, $3 \mathrm{mM} \mathrm{MgCl}$ 2, $80 \mathrm{nM}$ PGMY09 primer, $80 \mathrm{nM}$ biot PGMY11 primer, 20nM primer mix biot HLA-DQ, 200 $\mathrm{uM}$ of each dNTP and $0.025 \mathrm{U} / \mathrm{ml}$ Taq DNA polymerase (Fermentas). Amplification was performed using the following program: initial 3 min denaturation at $95^{\circ} \mathrm{C}$, followed by 45 cycles: $95^{\circ} \mathrm{C}, 30 \mathrm{sec}$ $/ 55^{\circ} \mathrm{C}, 90 \mathrm{sec} / 72^{\circ} \mathrm{C}, 120 \mathrm{sec}$, with a final $5 \mathrm{~min}$ extension at $72^{\circ} \mathrm{C}$. Subsequent typing was performed by reverse line hybridization (RLB) (CHUV), on a negatively charged nylon membrane and using specific biotinylated oligoprobes [24]. Hybrids detection was carried out by chemoluminescence using the ECL kit (Amersham) and following the manufacturer's specifications. The system's advantage is that it identifies $37 \mathrm{HPV}$ types and analyzes 40 samples in a single assay. This technique was validated by the WHO HPV LabNet.

\section{Detection of E6 and E7 oncogene messengers in lymph nodes}

The mRNA were detected with a reaction that combines amplification based on nucleic acid sequences (NASBA) and real-time detection (RealTime-PCR) using molecular beacon probes (NucliSENS EasyQ HPV, Biomerieux) which allow to detect the mRNA of E6 and E7 oncoproteins of the most frequent HPV genotypes in cervical cancer (HPVs: 16, 18, 31, 33 and 45). The protocol was followed according to the manufacturer's indications, adapting the methodology for biopsies since the kit is prepared for use with exfoliated cervical cells (as previously described in collection purification of lymph nodes' viral RNA).

Post-op follow-up: patients included in the study were prospectively followed-up for 3 years, using standard control protocols. All of them received neoadjuvant treatments.

\section{Results}

\section{Histological results}

Six adenocarcinomas (all stages IB1) and 39 squamous cell carcinomas (stage Ia: 1 case, IB1, 27 cases, IB2: 8 cases, IIA: 1case and IIIB: 2 cases) were histologically found.

\section{HPV detection and typing in tumors}

HPV was detected by PCR RLB in 42 tumors of 45 patients; the viral types identified were HPV16 ( $\mathrm{n}=32), \operatorname{HPV} 18(\mathrm{n}=5)$, HPV31 $(\mathrm{n}=3), \operatorname{HPV} 45(\mathrm{n}=2), \operatorname{HPV} 59(\mathrm{n}=1)$ and $\operatorname{HPV} 73(\mathrm{n}=1)$. These last 2 cases were not included in the study because the mRNA detection system does not include them. Also excluded were 2 patients whose tumors were HPV negative.

Table 1 shows the viral types found in tumors by PCR and RLB and in PLNs by mRNA E6-E7 detection. In 5 tumors mixed infections were detected, 2 cases with HPV $18+16,1$ case with HPV $16+18+31$ and 1 case with HPV $33+16$, although these were not found in the respective PLNs. However, in $100 \%$ of cases the type found in the PLN was the same as that detected in the tumor.

There was a high correlation between the histological and virological results (Table 2). 72\% of histologically positive PLN were positive for E6-E7 mRNA; while 93\% (125/134) of the negative PLN were also negative for E6-E7 mRNA assay. There was however $8 \%$ (9/134) of negative PLN in which viral messengers were detected.

Post-op monitoring: During the prospective 4 year assessment two patients died, one with positive PLNs by histology and E6-E7 mRNA, and the other with negative PLNs by both methods; in both cases, the viral type found in the primary tumor was HPV 45. In the remaining patients there have been no recurrences to date, even in the cases with positive PLN by histology and/or messengers detection.

\section{Discussion}

Due to up to $15 \%$ of patients with CC and PNL negatives develop recurrent-disease it is crucial to improve the detection of the occult metastatic spread of tumor cells. The presence of HPV in PLN may indicate metastases; since the virus is incapable of producing viremia or invading tissues, it can only be "transported" by the cancer cell. However, tests based on the DNA viral detection only provide information about the presence of infection and eventually the viral type, but if applied in PLN assessment, they cannot demonstrate its activity, its replication. Furthermore, the presence of viral DNA in PLN not necessarily implies

Table 1. Viral types found in tumors by PCR and RLB and in PLNs by E6-E7 mRNA

\begin{tabular}{|c|c|c|}
\hline HPV type & $\begin{array}{c}\text { Positive Tumors by } \\
\text { PCR-RLB n }=41\end{array}$ & $\begin{array}{c}\text { Positive PNLs by E6-E7 } \\
\text { mRNA }\end{array}$ \\
\hline HPV16 & $32(76 \%)$ & 24 \\
\hline HPV18 & $5(12 \%)$ & - \\
\hline HPV31 & $3(7 \%)$ & 2 \\
\hline HPV33 & $2(4,7 \%)$ & - \\
\hline HPV45 & $2(4,7 \%)$ & 6 \\
\hline HPV59 & $1(2,3 \%) *$ & - \\
\hline HPV73 & $1(2,3 \%)^{*}$ & - \\
\hline
\end{tabular}

PCR-RLB: In tumors, HPV genotyping was done by PCR-reverse hybridization using type-specific oligoprobes for 37 viral types.

E6 / E7 mRNA: In the lymph nodes (PLN), the detection of viral E6/E7 mRNAs for the five most common high risk HPV types in cervical cancer (HPVs 16, 18, 31, 33, and 45) was done.

In 5 tumors mixed infections were detected, 2 cases with HPV $18+16,1$ case with HPV $16+18+31$ and 1 case with HPV $33+16$, although these were not found in the respective PLNs.

Table 2. Correlation between the histology and E6 / E7 mRNA results

\begin{tabular}{|c|c|c|}
\hline Histology & E6/E7 mRNA (+) & E6/E7 mRNA (-) \\
\hline PNL positive $\left(\mathrm{n}^{\circ} 18\right)$ & $13(72 \%)$ & 5 \\
\hline PNL negative $\left(\mathrm{n}^{\circ} 134\right)$ & 9 & $125(93 \%)$ \\
\hline Total $\left(\mathrm{n}^{\circ} 152\right)$ & 22 & 130 \\
\hline
\end{tabular}

Histologically positive PLN: lymph nodes with lymph node metastasis. Histologically negative PLN: metastasis-free lymph nodes

E6 / E7 mRNA: In the lymph nodes (PLN), the detection of viral E6/E7 mRNAs for the five most common high risk HPV types in cervical cancer (HPVs 16, 18, 31, 33, and 45) was done. 
metastases because studies have shown that it could be the immune response result. In negative PLN, HPV DNA was found in nuclei and/ or cytoplasm of germinal centers' lymphocytes or cortical areas in the cells of endothelial capillaries, and macrophages [14].

The presence of viral mRNA indicates transcription of the viral genome; in a PLN it could only occur in metastatic cervical cancer cells because these viruses, as previously mentioned, are only able to replicate in epithelial cells. Most published studies referred to the detection HPV mRNA E6-E7 are related to cervical tissue disease and management

There are several published works that mention the detection of HPV 16 E6 / E7 transcripts in metastatic lymph node [25-27] they have applied RT-PCR techniques in fixed samples. In all the studies have indicated that the detection of viral mRNAS is a more sensitive indicator than the viral DNA to detect metastases [27]. Dürst M, and col. found that recurrence -free-survival was significantly longer for patients with HPV-negative PNL. In patients with cervical cancer and tumor-free lymph nodes by conventional histopathology HPVmRNA-positive PLN were of prognostic value independent of tumor size; they concluded that tumors larger than $20 \mathrm{~mm}$ diameter could possibly benefit from further risk stratification using HPV-mRNA as a molecular marker.

Although there is a history of RNA detection in cancers [28,29] , there are methodological difficulties associated with this type of test, because generally it requires working with fresh biological materials, RNase-free reagents and under conditions which protect RNA integrity and prevent contamination with cellular RNase and between samples.

The availability of a diagnostic commercial kit for detecting HPV E6-E7 mRNA, partly simplified experimental conditions in a Laboratory of Pathology. The assay used in this study allowed the detection of the RNA transcripts corresponding to viral oncoproteins E6-E7 of the $5 \mathrm{HPV}$ high risk types most frequent in cervical cancer worldwide: HPV 16, HPV 18, HPV 31, HPV 33 and HPV 45. This results in a higher positive predictive value than DNA tests as to the viral carcinogenic activity. Several studies have shown that these tests may be clinically useful because of their higher specificity for detecting cervical disease [30-32].

In our study HPV 16 was the most common viral type in tumors (76\%), and HPV 18 (12\%) was the second in prevalence. Other viral types were detected such as HPV 59 and HPV 71, cases that had to be excluded from the study because they are not present in the group detected by the E6- E7 mRNA. A high correlation was established between histological observation and virological results, since in $93 \%$ of histologically negative PLNs no viral messengers were detected; however, in 9 PLNs this methodology found evidence of a sub clinical metastasis unnoticed in the histological test. It should be noted that the biopsy blocks corresponding to these cases were trimmed as usual in anatomical pathology to confirm that there were no hidden-metastatic cells inside the tissue specimen.

In cases of histologically positive PLN, $72 \%$ of cases were confirmed, an acceptable sensitivity if it is considered the instability of RNA in clinical samples and their probable degradation during processing. On the other hand, the biopsy taken for mRNA analysis may be no representative of the whole node because the tumor cell distribution can be not homogeneous. The assay used in this study is designed for sloughed cells of the cervix, it therefore had to be validated for use in biopsy material (data not shown) which required further manipulation of the material with the resulting possibility of degradation.
Dürst $M$ et al. [27] has suggested that the presence of HPV E6E7 mRNA in sentinel PNL of patients with histological negative nodes, was associated with a decreased recurrence-free survival in 5 years follow-up. In our study the patients' follow-up was limited (4 years), and except for 2 deaths, in the period under consideration no recurrences were recorded in any of the enrolled patients. In a cohort study with more than 5,000 patients it was mentioned that the larger the lymphadenectomy, when PLNs were negative, the longer the survival; therefore lymphadenectomy could be of therapeutic value [17]. In our study, in cases with positive PLNs (histology or by mRNA detection) in early stages, the resection of tumors and lymph nodes could have removed malignant cells. On the other hand, it should also be noted that all patients received neoadjuvant therapy. A longer-term followup could confirm this.

Commercial kits for E6-E7 mRNA detection designed for cervical pathology may be applied also to evaluate PLN biopsies; the methodology is simple and may be carry out in low complexity hospital labs. The detection of HPV E6-E7 mRNA adds a diagnostic tool that may be used to complement histological findings, particularly when PLNs do not exhibit macroscopic and microscopic signs of invasion, thus optimizing monitoring and decision making.

\section{Acknowledgments}

We thank Silvia Nuñez and Joaquin González for their technical support.

\section{Grant support}

This study was supported by the Agencia Nacional de Promoción Científica y Tecnológica, National Ministry of Sciences, Argentina (PICT1259/2011)

\section{Conflict of interest}

All authors declare that they have not financial or other interest that is relevant to the subject matter under consideration in this article.

\section{Ethical approval}

The project was approved by Ethics Committee from each hospital participant.

\section{References}

1. Howley P. Papillomaviridae and their replication. (1996) The viruses and their replication. In: Fields B, Knipe D, Howley P et al. (Eds), Fields Virology, LippincottRaven Publishers ( $3^{\text {rd }}$ edn), Philadelphia: 2045-2070.

2. zur Hausen H, de Villiers EM (1994) Human papillomaviruses. Annu Rev Microbiol 48 427-447. [Crossref]

3. Bosch FX, Manos MM, Muñoz N, Sherman M, Jansen AM, et al. (1995) Study Group Prevalence of Human Papillomavirus in Cervical Cancer: a Worldwide Perspective. $J$ Natl Cancer Inst 87 796-802. [Crossref]

4. Khan MJ, Castle PE, Lorincz AT, Wacholder S, Sherman M, et al. (2005) The elevated 10 -year risk of cervical precancer and cancer in women with human papillomavirus (HPV) type 16 or 18 and the possible utility of type-specific HPV testing in clinical practice. J Natl Cancer Inst 97: 1072-1079. [Crossref]

5. Ciapponi A, Bardach A, Glujovsky D, Gibbons L, Picconi MA (2011) Type-specific HPV prevalence in cervical cancer and high-grade lesions in Latin America and the Caribbean: systematic review and meta-analysis. PLoS One 6: e25493. [Crossref]

6. Band D, Zajchowsky V, Kulesa R, Lager R (1990) Human papillomavirus DNAs immortalize normal human mamary epithelial cells and reduce their growth factor requirements. Proc Natl Acad Sci U S A 87 463-467. [Crossref]

7. Lazo PA, Gallego MI, Ballester S, Feduchi E (1992) Genetic alterations by human papillomaviruses in oncogenesis. FEBS Lett 300: 109-113. [Crossref] 
8. Lie AK1, Risberg B, Borge B, Sandstad B, Delabie J, et al. (2005) DNA- versus RNAbased methods for HPV detection in cervical neoplasia. Gynecol Oncol 97 908-915. [Crossref]

9. Molden T1, Kraus I, Karlsen F, Skomedal H, Nygård JF, et al. (2005) Comparison of HPV mRNA and DNA detection: a cross-sectional study of 4136 women $>30$ years of age with a 2-years follow-up of high grade sqamous intraepithelial lesion. Cancer Epidemiol Biomarkers Prev 14: 367-372. [Crossref]

10. Cuschieri KS, Whitley MJ, Cubie HA (2004) HPV type specific DNA and RNA persistence-implications for cervical disease progression and monitoring. J Med Virol 73: 65-70. [Crossref]

11. Kobayashi Y, Yoshinouchi M, Tianqi G, Nakamura K, Hongo A, et al. (1998) Presence of Human Papilloma Virus DNA in pelvic lymph nodes can predict unexpected recurrence of cervical cancer in patients with histologically negative lymph nodes. Clin Cancer Res 4: 969-983. [Crossref]

12. Slama J, Drazdakova M, Dundr P, Fischerova D, Zikan M, et al. (2011) High-risk human papillomavirus DNA in paraaortic lymph nodes in advanced stages of cervical carcinoma. J Clin Virol 50: 46-49. [Crossref]

13. Lukaszuk, Liss J, Gulczynski J, Nowaczyk M, Nakonieczny M, et al. (2007) Predictive value of HPV DNA in lymph nodes in surgically treated cervical carcinoma patients--a prospective study. Gynecol Oncol 104: 721-726. [Crossref]

14. Landro ME, Dalbert D, Picconi MA, Cúneo N, González J, et al. (2008) Human papillomavirus and mutated $\mathrm{H}$-ras oncogene in cervical carcinomas and pathological negative pelvic lymph nodes: a retrospective follow-up. J Med Virol. 80: 694-701. [Crossref]

15. Chan PK, Yu MM, Cheung TH, To KF, Lo KW, et al. (2005) Detection and quantitation of human papillomavirus DNA in primary tumour and lymph nodes of patients with early stage cervical carcinoma. J Clin Virol 33: 201-205. [Crossref]

16. Slama J, Fischerova D, Pinkavova I, Zikan M, Cibula D (2010) Human papillomavirus DNA presence in pelvic lymph nodes in cervical cancer. Int J Gynecol Cancer 20: 126-132.

17. Shah M, Lewin S, Deutsch I, Burke W, Sun X, et al. (2011) The therapeutic role of lymphadenectomy for cervical cancer. Cancer 117: 310- 317. [Crossref]

18. Averette HE, Nguyen HN, Donato DM, et al. (1993) Radical Hysterectomy for invasive cervical cancer: a 25 years prospective experience with the Miami technique. Cancer 71: 1422-1437. [Crossref]

19. Pearcey R, Dundas G, Schepansky A, Birchall I, Capstick V, et al. (1991) Is there a role for adyuvant radiotherapy alter radical hysterectomy in early stage cervical cancer? Int J Gynecol Cancer 2: 56. [Crossref]

20. Kinney WK, Alvarez RD, Reid GC, Schray MF, Soong SJ, el al. (1989) Value of adyuvant whole pelvis irradiatin alter WM hysterectomy for early stage squamous carcinoma of the cervix with pelvic nodal metastasis: a matched-control study. Gynecol Oncol 34 258-262. [Crossref]
21. Schorge JO, Molpus KL, Koelliker D, Nikrui N, Goodman A, et al. (1997) Stage Ib and IIa cervical cancer with negative lymph nodes: the rol of adyuvant radiotherapy after radical hysterectomy. Gynecol Oncol 66 31-35. [Crossref]

22. Sedlis A, Bundy BN, Rotman MZ, Lentz SS, Muderspach LI, et al. (1999) A randomized trial of pelvic radiation therapy versus no futher therapy in selected patients with stage IB carcinoma of the cervix after radical hysterectomy and pelvic linphadenectomy: a GOG Study. Gynecol Oncol 73: 177-183. [Crossref]

23. Manos MM, Ting Y, Wright DK, Lewis AJ, Broker TR, et al. (1989) The Use of Polymerase Chain Reaction Amplification for the Detection of Genital Papillomaviruses. Cancer Cells 7: 209-214.

24. Estrade C, Menoud PA, Nardelli-Haefliger D, Salí R (2011) Validation of a Low-Cost Human Papillomavirus Genotyping Assay Based on PGMY PCR and Reverse Blotting Hybridization with Reusable Membranes. J Clin Microbiol 49 3474-3481. [Crossref]

25. Rose BR, Thompson CH, JiangXM, TattersalMH, Eliott PM, et al. (1994) Detection of human papillomavirus type 16 E6/e7 transcripts in histologically cancer -free pelvic lymph nodes of patients with cervical carcinoma. Gynecol Oncol 52: 212-217. [Crossref]

26. Czeglédy J, Iosif C, Hansson BG, Evander M, Gergely L, et al. (1995) Can a test for E6/E7 transcripts of human papillomavirus type 16 serve as a diagnostic tool for the detection of micrometastasis in cervical cancer? Int J Cancer 64: 211-215. [Crossref]

27. Dürst M, Hoyer H, Altgassen C, Greinke C, Häfner N, et al. (2015) Prognostic value of HPV-mRNA in sentinel lymph nodes of cervical cancer patients with pN0-status. Oncotarget 6: 23015-23025. [Crossref]

28. Ayabe T, Tomita M, Matsuzaki Y, Ninomiya H, Hara M, et al. (2004) Micrometastasis and expression of nm23 messenger RNA of lymph nodes from lung cancer and the postoperative clinical outcome. Ann Thorac Cardiovasc Surg 10: 152-159. [Crossref]

29. Liang F, Qu H, Lin Q, Yang Y, Ruan X, et al. (2015) Molecular biomarkers screened by nextgeneration RNA sequencing for non-sentinel lymph node status prediction in breast cancer patients with metastatic sentinel lymph nodes. World J Surg Oncol 13: 258. [Crossref]

30. Nieves L, Enerson CL, Belinson S, Brainard J, Chiessa- Botero A, et al. (2013) Primary cervical cancer screening and triage using mRNA human papillomavirus assay and visual inspection. Int J Gynecol Cancer. 23 513-518. [Crossref]

31. Molden T, Kraus I, Karlsen F, Skomedal H, Nygard J, et al. (2005) Comparison of Human Papillomavirus Messenger RNA and DNA Detection: A Cross-sectional Study of 4,136 Women $>30$ Years of Age with a 2-Year Follow-up of High-Grade Squamous Intraepithelial Lesion. Cancer Epidemiol Biomarkers Prev 14 367-372. [Crossref]

32. Duvlis S, Popovska-Jankovic K, Arsova ZS, Memeti S, Popeska Z, et al. (2015) HPV E6/E7 mRNA versus HPV DNA biomarker in cervical cancer screening of a group of Macedonian women. J Med Virol 87: 1578-1586. [Crossref]

Copyright: (C2017 Basiletti JA. This is an open-access article distributed under the terms of the Creative Commons Attribution License, which permits unrestricted use, distribution, and reproduction in any medium, provided the original author and source are credited. 